УДК 631.22.

DOI: https://doi.org/10.36910/6775-2313-5352-2019-14-4

Банга В.I., к.т.н., Крупич О.М., к.т.н.

Львівський національний аграрний університет

\title{
МЕТОДИКА ЕКСПЕРИМЕНТАЛЬНИХ ДОСЛІДЖЕНЬ ВИМІРЮВАЧА МАСИ КОМБІКОРМУ В БУНКЕРІ ДОЗАТОРА
}

У статті наведено огляд і аналіз вимірювачів мас кормів, схему системи вимірювання та загальний вигляд вимірювача маси комбікорму в бункері дозатора, передбачено наявність засобів для вимірювання, реєстрачії та передачі інформації електричними сигналами біжучих значень маси комбікорму в бункері дозатора в динамічному режимі, відображення $і$ зберігання інформачії та контрольно-вимірювальні прилади.

Подано експериментальну установку та методику експериментальних досліджень вимірювача маси комбікорму з використанням теорії багатофакторного планованого експерименту, наведено рівні варіювання факторів, матрицю плану експерименту, рівняння регресії для визначення вихідної напруги вимірювача маси комбікорму в бункері дозатора від зміни зусилля згинального моменту тензовимірювальної площиини.

Запропонована методика експериментальних досліджень вимірювача маси комбікорму в бункері дозатора з використанням теорії планованого експерименту дає змогу встановити оптимальні значення досліджуваних факторів (площу поперечного перерізу $i$ довжину тензовимірювальної площини та величину згинального моменту тензовимірювальної площини), підвищити достовірність результатів експерименту.

Ключові слова: вимірювач маси, дозатор, комбікорм, експериментальна установка, планований експеримент, вихідна напруга, тензодатчик

Постановка проблеми. У технологічному процесі дозування комбікормів виникає потреба у вимірюванні рівня висоти сипких кормів а також сигналізації мінімально чи максимально допустимих рівнів у бункерах.

Вимірювання маси комбікорму в бункері дозатора є одним із важливих його показників які можуть мати вплив на продуктивність, рівномірність i точність дозування. У технологічному обладнанні, яке використовується для дозування сипких кормів, використовуються вимірювачі рівня в яких відхилення похибки вимірювання перевищує встановлені зоотехнічні вимоги на технологічний процес. Тому розробка методики вимірювання маси комбікормів в бункері дозатора $є$ актуальним і перспективним.

Аналіз останніх досліджень і публікацій. Вимірювання рівня сипких мас має свої особливості. Характерною відмінністю сипких мас від рідких є непропорціональність передачі тиску на дно і стінки бункера в залежності від рівня висоти. Властивість сипких кормів утворювати при насипанні кут природного укосу дозволило створити серію маятникових вимірювачів, які працюють за принципом відхилення матеріалом чутливого елемента 3 жорсткою або гнучкою підвіскою. Огляд і аналіз існуючих конструкцій вимірювачів сипких кормів [1-3] показав, що існуючі вимірювачі рівня маятникового, вагового типу та мембранний датчик типу МДУ-3М не забезпечують відповідної похибки вимірювань, мають значну металоємність та вартість, складні за конструкцією. Відсутня методика експериментальних досліджень.

Постановка завдання. Наше завдання - підвищення точності вимірювання шляхом вдосконалення конструкції та визначення вихідної напруги вимірювача маси комбікорму в бункері дозатора від зміни зусилля згинального моменту тензовимірювальної площини.

Виклад основного матеріалу. Для дослідження впливу зміни маси комбікорму в бункері на продуктивність і рівномірність індивідуального дозатора у процесі досліджень був розроблений вимірювач маси комбікорму, схема системи вимірювання маси комбікорму та блок-схема і загальний вигляд вимірювача якого показані на рис. 1, 2, 3 [4 ].

В основу винаходу поставлена задача створення такого вимірювача маси комбікорму, в якому нове виконання вимірювального елементу дозволить спростити конструкцію вимірювача, зменшити металомісткість та підвищити точність вимірювання. 


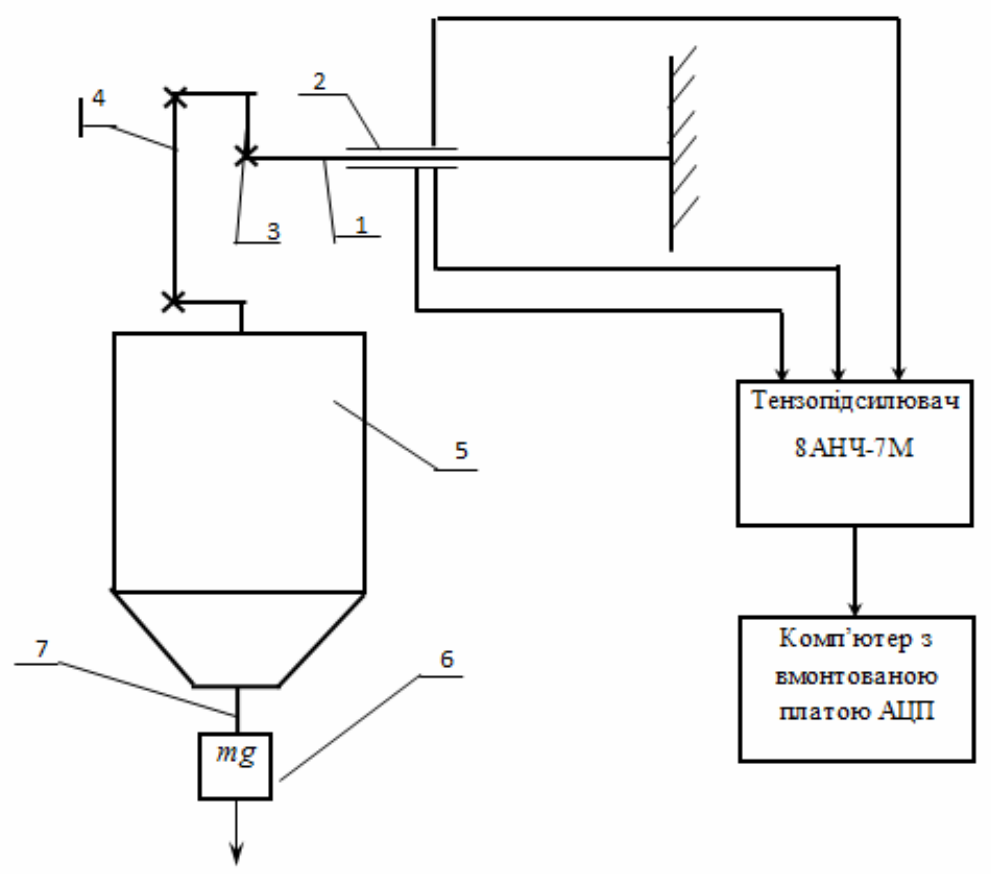

Рис. 1. Схема системи вимірювання маси комбікорму в бункері дозатора:

1 - пружна пластина; 2 - тензодавачі; 3 -призма; 4 -підвіска; 5 -бункер індивідуального дозатора; 6 - гиря; 7 - нитка підвісу гир.

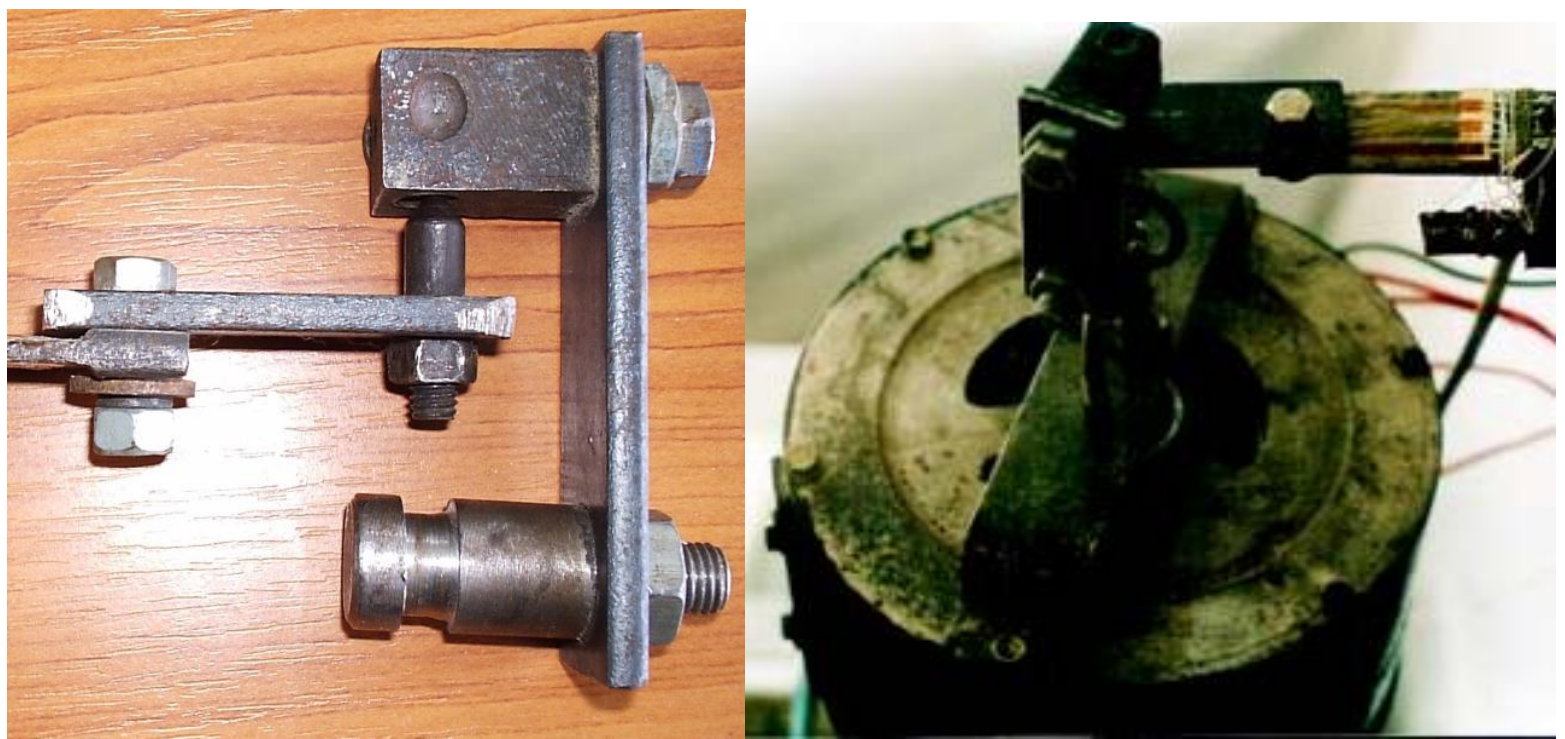

Рис. 2. Загальний вигляд вимірювача маси комбікорму в бункері дозатора

Вимірювач маси комбікорму містить тензовимірювальну пружну пластину 1 яка закріплена жорстко на якій наклеєні тензодатчики 2 які з'єднані в мостову схему. До пружної пластини 1 закріплено призму 3, на до якої підвішена підвіска 4 з бункером дозатора комбікормів.

Дослідження проводили у такій послідовності. Сипкий матеріал завантажувався в приймальний бункер 5 дозатора . 3 бункера 5 комбікорм подавався на робочий орган дозатора. При зміні маси комбікорму в бункері тензовимірювальна пружна пластина 1 прогиналася. Прогин фіксувався тензодавачами 2. Сигнал, який надходив від вимірювальної площини 1 , як це показано на рис. 1 , підсилювався тензопідсилювачем. Результуючі сигнали сприймав блок аналогово-цифрового перетворення L-154, який встановлений в комп’ютер. Запис реалізації випадкового процесу вимірювання маси комбікорму відображався на моніторі комп'ютера. Інформація в цифровому вигляді записувалася у файл досліджень, а за необхідності 
виводилася на принтер.

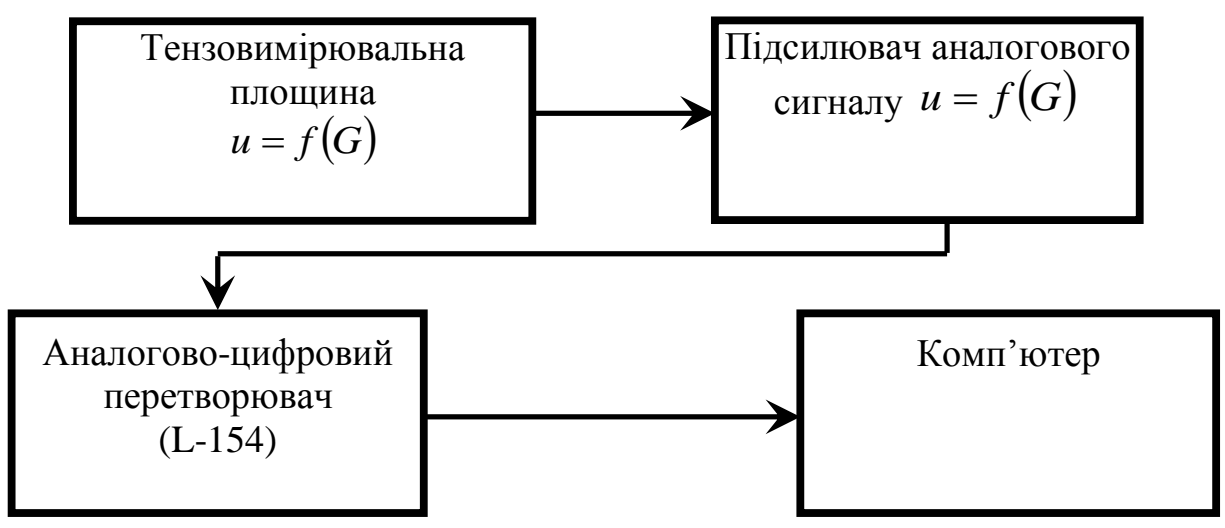

Рис. 3. Блок-схема вимірювання маси комбікорму в бункері дозатора

Загальний вигляд комп'ютера з вмонтованою платою АЦП L-154 наведено на рис. 4.

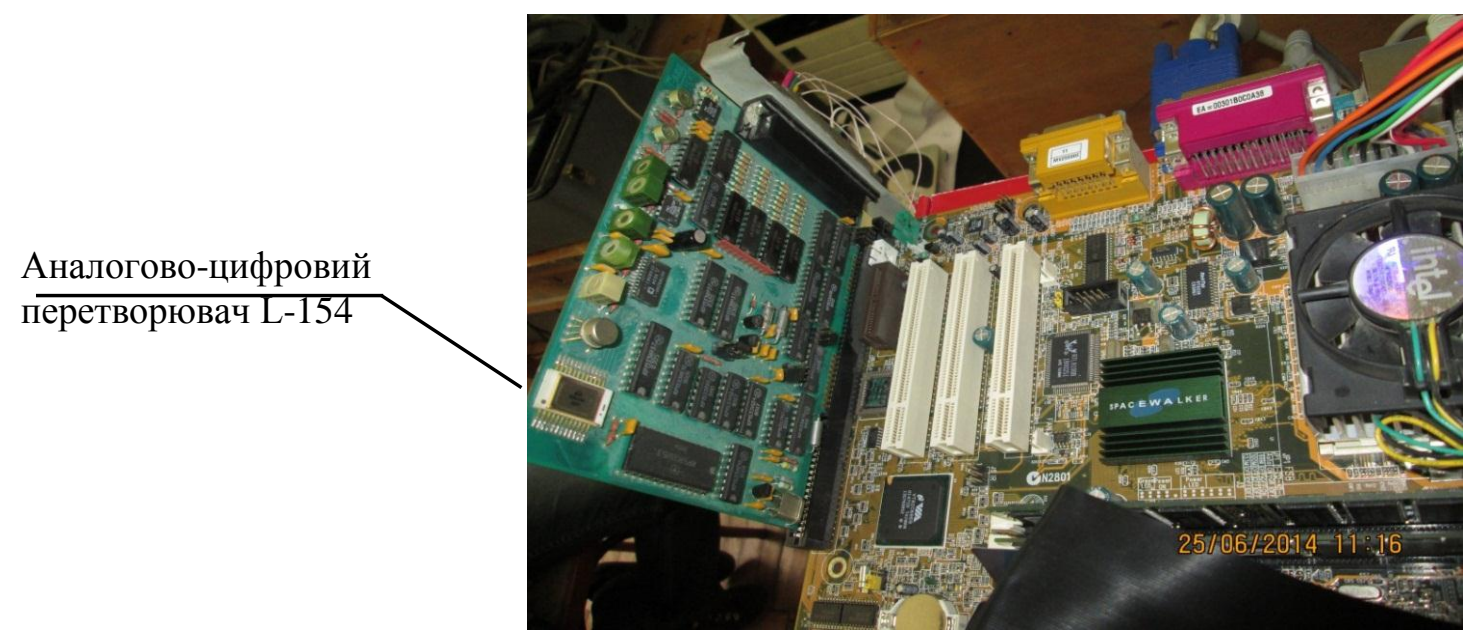

Рис. 4. Загальний вигляд материнської плати комп’ютера з вмонтованою платою АЦП L-154

Основними перевагами запропонованої методики порівняно з існуючими $є$ синхронна 3 роботою вимірювача маси комбікорму обробка результатів досліджень і відображення на моніторі комп'ютера або створення твердих копій процесу вимірювання у вольтах (B).

Для обгрунтування конструктивно-технологічних розмірів тензовимірювальної площини необхідно провести повний трифакторний планований експеримент на трьох рівнях типу $3^{\kappa}$, (к - число факторів) плану другого порядку Бокса-Бенкіна за відомою методикою [5; 6]. Інтервали і рівні варіювання факторів наведені в табл. 1, а матриця плану у табл. 2.

Таблиця 1

Інтервали і рівні варіювання факторів

\begin{tabular}{|c|c|c|c|c|}
\hline $\begin{array}{c}\text { Рівень варіювання } \\
\text { факторів }\end{array}$ & $\begin{array}{c}\text { Кодовані } \\
\text { значення }\end{array}$ & $\begin{array}{c}\text { Площа } \\
\text { поперечного } \\
\text { перерізу } S, \mathrm{~m}^{2}\end{array}$ & $\begin{array}{c}\text { Довжина } \\
\text { тензовимірювальноі } \\
\text { площини } L, \mathrm{M}\end{array}$ & $\begin{array}{c}\text { Згинальний } \\
\text { момент } \\
\text { тензовимірю- } \\
\text { вальної площини } \\
\text { п, Н·м }\end{array}$ \\
\hline Верхній & + & 0,2 & 0,160 & 9,4 \\
\hline Основний & 0 & 0,145 & 0,120 & 5,09 \\
\hline Нижній & - & 0,09 & 0,080 & 0,78 \\
\hline $\begin{array}{c}\text { Інтервал } \\
\text { варіювання }\end{array}$ & $\varepsilon$ & 0,055 & 0,04 & 4,31 \\
\hline
\end{tabular}

(C) Банга B.I., к.т.н., Крупич О.М., к.т.н. 
Таблиця 2

Матриця плану експерименту

\begin{tabular}{|c|c|c|c|c|}
\hline \multirow{2}{*}{$№$ експерименту } & \multicolumn{3}{|c|}{ Варіювання факторами } & Критерій оптимізації \\
\cline { 2 - 5 } & $x_{1}$ & $x_{2}$ & $x_{3}$ & $U, \mathrm{~B}$ \\
\hline 1 & 1 & 1 & 0 & $y_{1}$ \\
2 & -1 & -1 & 0 & $y_{2}$ \\
3 & 1 & -1 & 0 & $y_{3}$ \\
4 & -1 & 1 & 0 & $y_{4}$ \\
5 & 0 & 1 & 1 & $y_{5}$ \\
6 & 0 & -1 & -1 & $y_{6}$ \\
7 & 0 & 1 & -1 & $y_{7}$ \\
8 & 0 & -1 & 1 & $y_{8}$ \\
9 & 1 & 0 & 1 & $y_{9}$ \\
10 & -1 & 0 & -1 & $y_{10}$ \\
11 & 1 & 0 & -1 & $y_{11}$ \\
12 & -1 & 0 & 1 & $y_{12}$ \\
13 & 0 & 0 & 0 & $y_{13}$ \\
14 & 1 & 1 & 1 & $y_{14}$ \\
15 & -1 & -1 & -1 & $y_{15}$ \\
16 & -1 & 1 & 1 & $y_{16}$ \\
17 & -1 & -1 & 1 & $y_{17}$ \\
18 & -1 & 1 & -1 & $y_{18}$ \\
19 & 1 & -1 & -1 & $y_{19}$ \\
20 & 1 & -1 & 1 & $y_{20}$ \\
21 & 1 & 1 & -1 & $y_{21}$ \\
22 & 0 & 0 & -1 & $y_{22}$ \\
23 & 0 & 0 & 1 & $y_{23}$ \\
24 & 0 & 1 & 0 & $y_{24}$ \\
25 & 0 & -1 & 0 & $y_{25}$ \\
26 & 1 & 0 & 0 & $y_{26}$ \\
27 & -1 & 0 & 0 & $y_{27}$ \\
\hline
\end{tabular}

За критерій оптимізації прийнято вихідну напругу тензодатчиків $U$ вимірювача маси. Факторами, які впливають на вихідну напругу тензодатчиків $U$, були площа поперечного перерізу $S$, довжина тензовимірювальної площини $L$, згинальний момент тензовимірювальної площини $M$.

Перед початком експерименту вибирали межі зміни факторів та провели їх кодування.

Кодування факторів проводили за формулою [5; 6]:

$$
x_{i}=\frac{\mathrm{X}_{i}-X_{0 i}}{\varepsilon}
$$

де $x_{i}$-кодоване значення фактору (безрозмірна величина), верхній рівень позначається +1 , нижній -1 (в центрі експерименту нульовий рівень); $X_{i}$ - натуральне значення фактору; $X_{i 0}-$ натуральне значення фактору на нульовому рівні; $\varepsilon$-інтервал варіювання.

Інтервал варіювання визначали за формулою [5]:

$$
\varepsilon=\frac{x^{\mathrm{B}}-x^{\mathrm{H}}}{2},
$$

де $x^{B}, x^{H}$-значення $i$-го фактору на верхньому і нижньому рівнях.

Рівняння регресії для трифакторної моделі доцільно шукати у наступній формі [12-14]:

$$
\hat{y}=b_{0}+b_{1} x_{1}+b_{2} x_{2}+b_{3} x_{3}+b_{11} x_{1}^{2}+b_{22} x_{2}^{2}+b_{33} x_{3}^{2}+b_{12} x_{1} x_{2}+b_{13} x_{1} x_{3}+b_{23} x_{2} x_{3}+b_{123} x_{1} x_{2} x_{3} .
$$

Для використання (3) в розрахунку проводили відповідні перетворення лінійних членів рівняння з кодованих значень в натуральні, які визначили за формулою [5]: 


$$
b_{i} x_{i}=\frac{b_{i}}{\varepsilon_{i}} X_{i}-\frac{b_{i}}{\varepsilon_{i}} X_{0 i}
$$

Перетворення лінійних членів рівняння, які взаємодіють, проводили за формулою [5]

$$
b_{i j} x_{i} x_{j}=\frac{b_{i j}}{\varepsilon_{i} \varepsilon_{j}}\left(X_{i} X_{j}-X_{i} X_{0 j}-X_{j} X_{0 i}+X_{0 i} X_{0 j}\right) .
$$

Для перетворення квадратних членів використовували формулу:

$$
b_{i i} x_{i} x_{i}^{2}=\frac{b_{i i}}{\varepsilon_{i}{ }^{2}}\left(X_{i}^{2}-2 X_{i} X_{0 i}+X_{0 i} X_{0 i}^{2}\right) .
$$

Коефіцієнти регресії визначали з використанням ПЕОМ у редакторі Excel.

Перевіряли математичні моделі на однорідність дисперсій або на відтворення дослідів за виконання умови [ $5 ; 7]$

$$
G_{p o s}\left\langle G_{m a \tilde{\sigma}},\right.
$$

де $G_{\text {роз }}, G_{\text {таб }}-$ розрахункове і табличне значення критерію Кохрена, яке вибирається з таблиці дод. 2 для рівня значущості 0,05 [5].

$G_{\text {роз }}$ - критерій Кохрена з числом степенів вільності для чисельника [5]:

$$
f_{u}=c-1, \quad \text { знаменника } f_{3}=N_{p},
$$

де $\boldsymbol{C}$ - число повторностей досліду;

$N_{p}$ - число рядків плану.

Розрахункове значення критерію Кохрена $G_{\text {роз }}$ визначаємо зі співвідношення [5; 7]:

$$
G_{p o 3}=\frac{S_{n}^{2} \max }{\sum_{n=1}^{N_{p}} S_{n}{ }^{2}},
$$

де $S_{n}^{2} \max$ - максимальне значення рядкової дисперсії;

$$
\sum_{n=1}^{N_{p}} S_{n}{ }^{2} \text { - сумарне значення за рядковими дисперсіями. }
$$

Визначали дисперсію $S_{y}{ }^{2}$, яка характеризує похибки дослідів у матриці плану за формулою [7]:

$$
S_{y}{ }^{2}=\frac{\sum_{u=1}^{N_{p}} \sum_{i=1}^{m}\left(y_{i u}-\bar{y}\right)^{2}}{N_{p} \cdot(m-1)},
$$

де $y_{i u}-$ значення критерію оптимізації в паралельних дослідах (в $u$-му рядку);

$\bar{y}-$ середнє значення критерію оптимізації в паралельних дослідах $\quad$ в $u$-му рядку матриці плану;

$m$ - кількість повторностей одного досліду (одного рядка матриці плану).

Перевірку на адекватність моделі проводили за критерієм Фішера $F_{p o s}$. Модель $\epsilon$ адекватною, якщо виконується умова: $F_{\text {роз }}\left\langle F_{\text {таб }}\right.$ [5], де $F_{p о з}, F_{\text {таб }}-$ розрахункове і табличне значення критерію Фішера, яке вибирається з табл. дод. 3 для рівня значущості 0,05 з числом степенів вільності чисельника $f_{u}=N_{p}-d$, знаменника $f_{3}=N_{p} \cdot(m-1)[5,7]$.

де $d$-кількість значущих коефіцієнтів.

Розрахункове значення критерію Фішера $F_{\text {роз }}$ визначаємо з відношення [6]:

$$
F_{p o 3}=\frac{S_{a d}{ }^{2}}{S_{y}{ }^{2}},
$$

де $S_{a d}{ }^{2}-$ дисперсія адекватності;

Дисперсія адекватності $S_{a \partial}{ }^{2}$ визначається як [6]: 


$$
S_{a \partial}^{2}=\frac{\sum_{u=1}^{N_{p}}\left(\hat{y}_{u}-\bar{y}\right)^{2}}{N_{p}-d},
$$

де $\hat{y}_{u}$ - розрахункове (за рівнянням регресії) значення параметра оптимізації.

Висновки. Запропонована методика експериментальних досліджень вимірювача маси комбікорму в бункері дозатора 3 використанням теорії планованого експерименту дає змогу встановити оптимальні значення досліджуваних факторів

(площу поперечного перерізу, довжину тензовимірювальної площини, величину згинального моменту тензовимірювальної площини), підвищити достовірність результатів експерименту.

\section{Інформаційні джерела:}

1. Зайцев С.А., Грибанов Д.Д., Толстов А.Н. и др. Контрольно-измерительные приборы и инструменты : учебное пособие. Москва: Издательский центр «Академия», 2006. $464 \mathrm{c}$.

2. Раннев Г.Г. ,Тарасенко А.П. Методы и средства измерений : учебник для вузов. 3-е изд., стер. Издательский центр «Академия», 2006. 336 с.

3.Дивин А.Г., Пономарев С.В., Мозгова Г.В. Методы и средства измерений, испытаний и контроля : учебное пособие. В 5 ч. - Тамбов : Изд-во ФГБОУ ВПО «ТГТУ», 2012. - Ч. 2. 108 c

4.Банга B.I. Матеріали V-ї Науково-технічної конференції «Технічний прогрес у тваринництві та кормовиробництві». ННЦ IMEСГ НАAН України. Глеваха. 2016. URL: htt://animal-conf.inf.ua/conf.html (дата звернення 16.12.2016 p.)

5. Мельников С. В., Алешкин В. Р., Рощин П. М. Планирование эксперимента в исследованиях сельскохозяйственных процессов. Ленинград: Колос, 1980. 163 с.

6. Львович Я. Е., Фролов В. Н. Теоретические основы конструирования, технологии и надежности РЭА. Москва: Радио и связь, 1986. 192 с.

7. Бондар А.Г. , Статюха Г.А., Потяженко И. А. Планирование эксперимента при оптимизации процессов химической технологии. Київ. Вища школа, 1980. 261 с.

Банга В.И., к.Т.Н., Крупыч О.М., к.т.н.

Львовский национальный аграрный университет

\section{МЕТОДИКА ЭКСПЕРИМЕНТАЛЬНЫХ ИССЛЕДОВАНИЙ ИЗМЕРИТЕЛЯ МАССЫ КОМБИКОРМА В БУНКЕРЕ ДОЗАТОРА}

В статье приведен обзор и анализ измерителей масс кормов, схему системы измерения и общий вид измерителя массы комбикорма в бункере дозатора, предусмотрено наличие средств для измерения, регистращии и передачи информачии электрическими сигналами бегущих значений массы комбикорма в бункере дозатора в динамическом режиме, отображение и хранение информачии и контрольно-измерительные приборы.

Подано экспериментальную установку и методику экспериментальных исследований измерителя массы комбикорма с использованием теории многофакторного планируемого эксперимента, приведены уровни варьирования факторов, матрииу плана эксперимента, уравнения регрессии для определения выходного напряжения измерителя массы комбикорма в бункере дозатора от изменения усилия изгибающего момента тензоизмерительной плоскости.

Предложенная методика экспериментальных исследований измерителя массы комбикорма в бункере дозатора с использованием теории планируемого эксперимента позволяет установить оптимальные значения исследуемых факторов (площадь поперечного сечения и длину тензоизмерительной плоскости и величину изгибающего момента тензоизмерительной плоскости), повысить достоверность результатов эксперимента.

Ключевые слова: измеритель массы, дозатор, комбикорм, экспериментальная установка, планируемый эксперимент, выходное напряжение, тензодатчик.

Banha V.I., Ph.D., Krupych O.M., Ph.D.

Lviv National Agrarian University

METHOD OF EXPERIMENTAL RESEARCHES OF MEASUREMENT OF COMBIQUE MASS IN THE BREAKING BOOKER

(C) Банга B.I., к.T.Н., Крупич О.М., к.т.н. 
The article provides an overview and analysis of feed mass meters, a scheme of measurement systems and a general view of the mass of mixed feed in the hopper hopper, provides for the availability of means for measuring, recording and transmitting information by electric signals of running values of the mass of mixed feed in the hopper of the dispenser in a dynamic mode, displaying and storing information and control devices.

The experimental setting and the method of experimental studies of the mass of the mixed fodder meter using the theory of the multifactor planned experiment are given, the variance levels of the factors, the experiment plan matrix, the regression equation for determining the output voltage of the mass of the mixed fodder in the hopper of the dispenser from the change in the bending force of the tensile measuring plane are given.

The proposed technique of experimental studies of the mass of a mixed fodder in a hopper of a dispenser using the theory of the planned experiment allows us to determine the optimal values of the investigated factors (the area of the cross section and the length of the tensiometric plane and the magnitude of the bending moment of the tensiometric plane), to increase the reliability of the experimental results.

Key words: mass meter, dispenser, mixed fodder, experimental installation, planned experiment, output voltage, strain gauge. 